\title{
EVALUATION OF ROOT CANAL OBTURATION RESULTS WITH THE CANAL SHAPING SYSTEM WAVE ONE AND GUTTA THERMAFIL
}

\author{
Ta Anh Cuong*, Ngo Thi Huong Lan*, Steven Wijaya*, Ta Thu Anh*
}

\section{ABSTRACT}

Objective: To evaluate the results of root canal obturation with Wave One (WO) canal shaping system and Gutta Thermafil obturation system. Design: Nonrandomized prospective experimental trial between December 2020 and March 2021. Setting: Central Military Hospital 108. Subject: 30 lower incisors extracted teeth without stem rupture, without root damage such as fracture, stray, fissure. Results: The number of slices with the biggest gaps accounting for $16.7 \%$. The number of slices with the smallest gaps accounting for $10 \%$. The number of slices with gaps over the total slices accounted for $14.4 \%$. The void area in the apical slice was $1,413 \pm 519.5 \mu \mathrm{m} 2$ and the largest void area was 38,654.2 $\pm 3,939.8 \mu \mathrm{m} 2$. Conclusion: Thermafil Gutta Percha has a good fit to the canal wall, which can seal the canal more easily and accurately.

Keywords: Root canal, Wave One, Thermafil.

\section{INTRODUCTION}

In dentistry, canal obturation is one of the key factors determining the success of root canal treatment. The canal forming systems, types of obturation are always researched to produce the best results. However, the evaluation in clinical results is still difficult, so we conducted this study to evaluate the ability of the canal's sealing in experiments

* 108 Military Central Hospital

Responsible person: Ta Anh Cuong

Email: taanhtuan108@gmail.com

Date of receipt: $15 / 5 / 2021$

Date of scientific judgment: $26 / 6 / 2021$

Reviewed date: $31 / 7 / 2021$ of the Wave One (WO) and Gutta Themafil canal shaping systems. The teeth are demineralized, sliced and then examined on a scanning electron microscope.

\section{MATERIALS AND METHODOLOGY}

Research method: Using experimental methods in the laboratory.

The subjects were 30 lower incisors extracted teeth from elder people. The inclusion criteria were teeth extracted without stem rupture, without root damage such as fracture, stray, fissure.

Materials and experimental research facilities:

- The set of examination trays: Mouth mirror, Cotton Forceps, and Endodontic Explorer.

- High-speed hand-piece, WO motor and hand-piece

- The burs to open the canal: Round diamond bur and Endo-Z.

- Endodontic ruler

- K-files No.10, 15, 20, ...

- WO files.

$-0.9 \% \mathrm{NaCl}$ solution, $3 \% \mathrm{NaOCl}$ and Glyde.

- Paper Point.

- Gutta Thermafil.

- Thermaprep 2 Oven 230V Thermaprep from Densply Maillefer.

- Digital X-ray. 


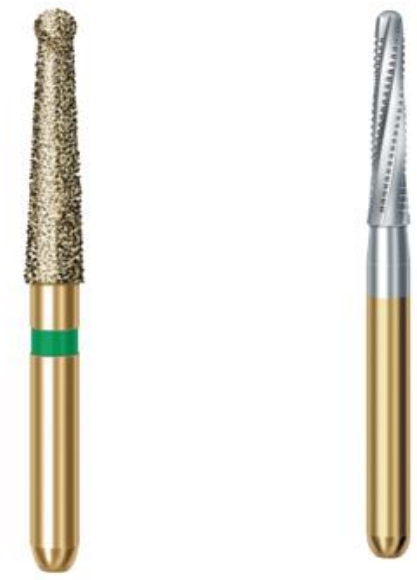

Figure 1: Round diamond bur and Endo-Z

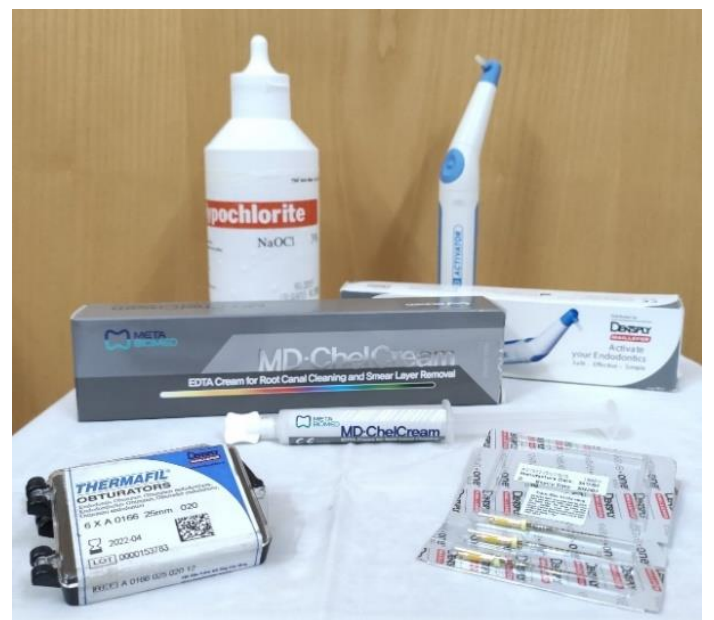

Figure 2: $\mathrm{NaOCl} 3 \%$, Dentsply EndoActivator, MD-ChelCream, Thermafil Gutta Percha, WO file

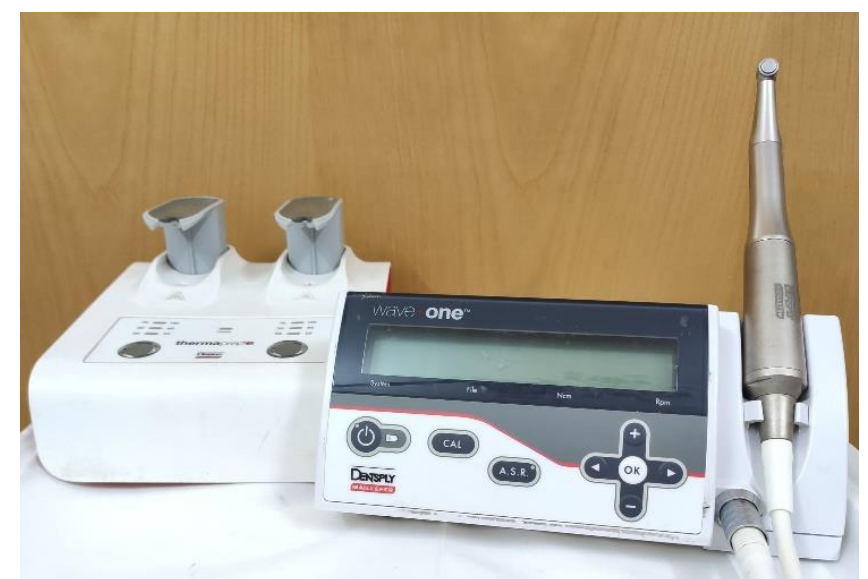

Figure 3: Dentsply Wave One system and Dentsply Thermaprep 2 Oven 


\section{VIETNAM MEDICAL JOURNAL № $1 \& 2 / 2021$}

Teeth have been prepared as following:

- Teeth are cleaned by soaking in $3 \% \mathrm{NaOCl}$ solution for 24 hours to remove residues around the root. Flushing for 1 hour.

- Shaping the canal with a Wave One brooch and flushing the canal with the Endo Activator system with $3 \% \mathrm{NaOCl}$ solution.

- Canal Obturation: using WOMGP (wave one matching gutta - percha point) technique.

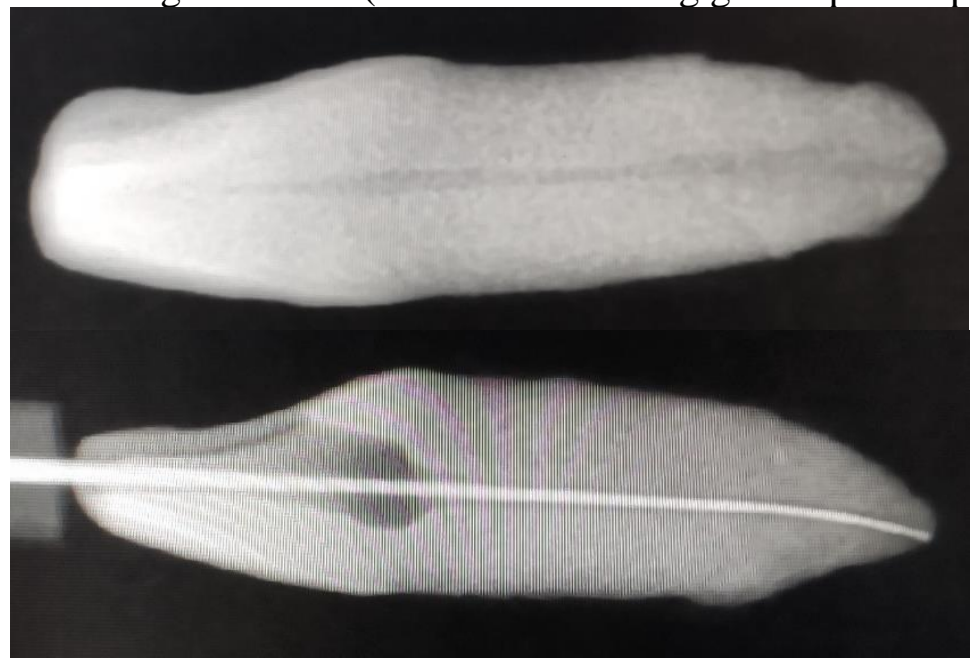

Figure 4: X-ray before and after access opening

Demineralization solutions include:

- Mixture with equal volume between $40 \%$ formic acid and $20 \%$ sodium-citrate.

- Nitric acid 5\%.

- The mixture is made up of 8 parts by volume of hydrochloric acid 38\%, 10 parts by volume of formic acid $85 \%$, and 82 parts by volume of distilled water.

- EDTA solution $14 \%$.

- Scanning electron microscope (Scanning Electron Microcopy - SEM).

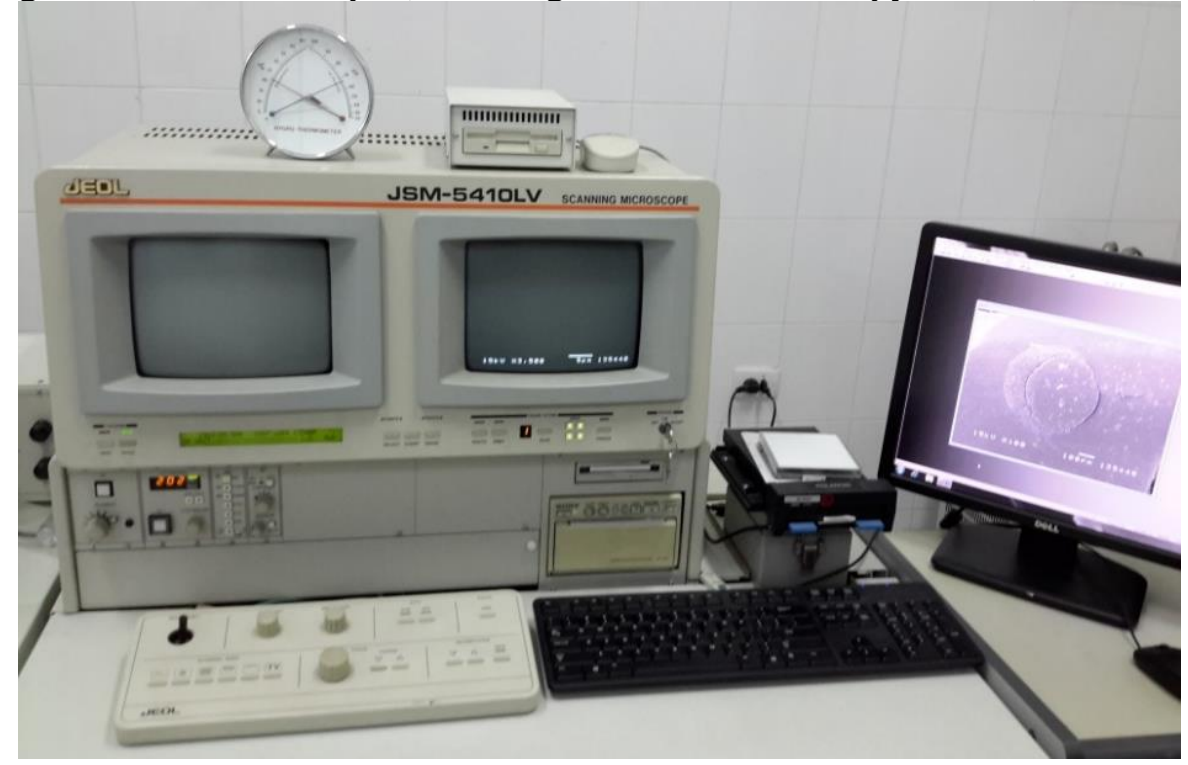

Figure 5: Scanning electron microscope 
After obturation, the samples were demineralized, sliced and then examined at the Morphology Department (Institute 69, Mausoleum Command) as follows:

- Tooth demineralized with $\mathrm{HNO}_{3}$ solution of $5 \%$ ratio of volume: $1 / 10$. The elimination time is about 3 days on average. Check by inserting needle into tooth root, if soft. Cut the middle $1 / 3$ of the tooth with a surgical knife.

- Then, rinse with running water for 1 hour. Transfer the sample to 50, 70, 80, 96, and 100\% alcohol. Time: 1 hour / 1 concentration. device.

- A critical point drying in a drying

- Attach the sample to the sample carrier, plated with gold on the metal evaporator.
- Scanning on a scanning electron microscopy (scanning electron microscopy SEM).

Divide gutta percha bar into 3 parts: 1 control, 1 soak for 3 days and 1 soak for 6 days ( 2 times the normal demineralization time). The control was dried with a critical point drying device, plated with metal and examined for the surface under a scanning electron microscope. Part 2, soak in 5\% $\mathrm{HNO}_{3}$ solution with volume $1 / 10$ for 6 days (2 times the normal demineralization time). After sufficient immersion for sufficient time, the samples were rinsed with running water for 1 hour, allowed to dry with a pointto-cavity drying device, plated with metal and examined under the scanning electron microscope.

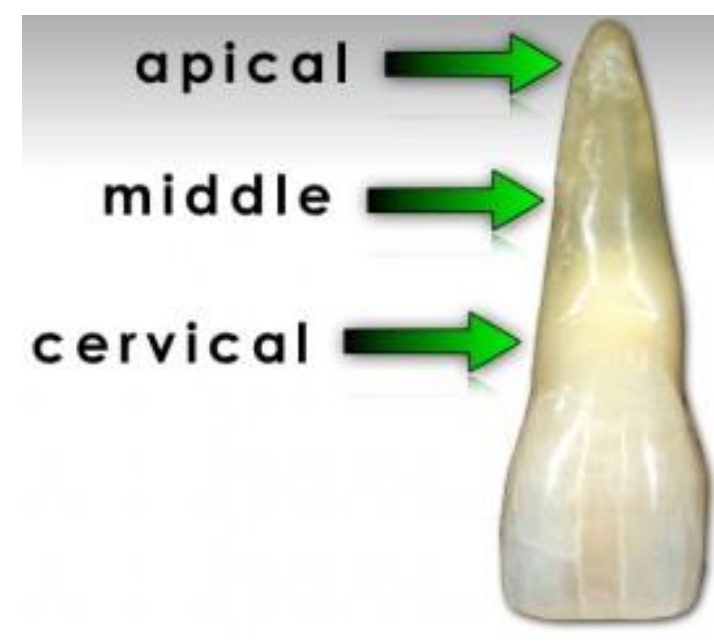

Figure 6: Slices through the root

\section{RESULTS AND DISCUSSION}

The number of slices with gaps was most encountered in the cervical slices, having $5 / 30$ cases, accounting for $16.7 \%$. In the position of the apical slice, the number of slices with the least gaps, 3/30 cases, accounting for $10 \%$. The number of slices with gaps over the total slices accounted for $14.4 \%$. The results showed that the void area in the apical slice was the smallest (average $1,413 \pm 519.5 \mu \mathrm{m} 2)$ and the largest void area was in the middle slice of the OT (mean $38,654.2 \pm 3,939.8 \mu \mathrm{m} 2$ ). The ratio of the void area to the total OT area in the cervical, middle and apical slice locations is $1.62 \pm$ $1.4 \%$, respectively; $4.48 \pm 0.6 \%$ and $0.25 \pm$ $0.4 \%$. 


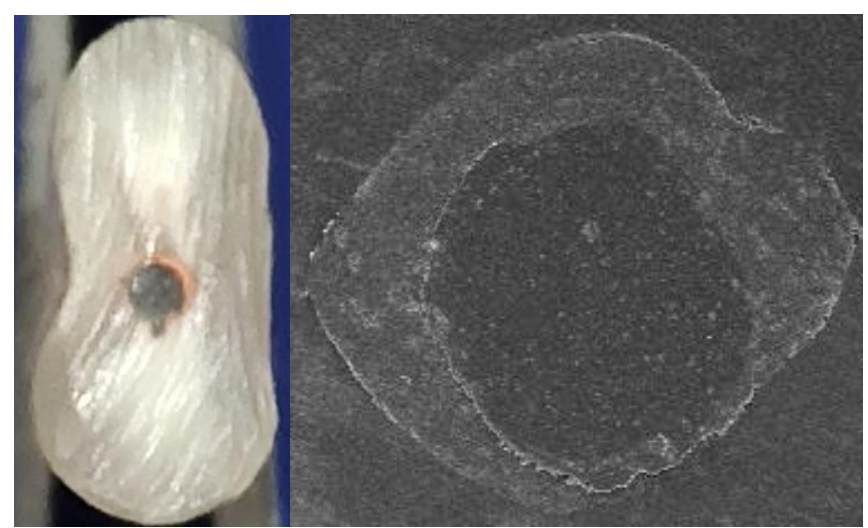

Figure 7: Tooth slices after obturation

Some authors have surveyed by creating a section of $1 / 3$ under the root of the tooth with a diamond-fitted door, the results found that the obturations surface were not clear, creating an obtuse angle, curving on one side, and the opposite side creating ragged strips, beams out into the canal. The canal walls were clear. Reclining surface clearly shows that the cuts were relatively parallel to each other. The space between the obturation surface and the canal wall was narrow, of irregular size, partially obscured, containing measles-like components.

The obturation was located in the center, the surface was clear, without distortion. The margins of the canal walls were sharp. The space between the obturation and the canal wall was uniform in size, not obstructed. Clean surface, no foreign bodies, no parallel cuts.

Thus, the use of diamond disc gave the section a dishonest image such as: the obturation was deformed in the cutting direction. This results in the size of the gap between the obturation and the canal wall being wider, difficult to determine (the obturation edge is curved and confined on one side), or indeterminate (on the opposite side) due to the obturation mask covered. Although it was cooled by water, in our opinion, the obturation was partially heat deformed, on the other hand it was deformed due to the movement of the saw blade. On the contrary, in teeth after demineralization, the obturation as well as the obturation assembly - the gaps - the canal wall is not deformed and clearly defined when studying.

Effect of demineralization solution on gutta percha.

The gutta percha surface had a flat structure, was made up of thin layers, fragments of small and irregular sizes. After soaking in $\mathrm{HNO}_{3}$ solution for 3 days, the surface structure did not change, compared with the control, the surface was flat, there was no sign of destruction.

Through the surface image of gutta percha we saw that $\mathrm{HNO}_{3}$ causes an impact on the surface of gutta percha increasing over time. After 3 days of soaking in the solution, we have not seen any changes changing surface morphology. For samples soaked for 6 days, the surface of the sample had relatively clear changes: the surface was no longer flat, with small holes in the low concave areas. Thus, $\mathrm{HNO}_{3}$ affected the surface structure of gutta percha, and depends on time. Verdenius H.H.W., Alma L., (1958) when quantitative research on substances, demineralization method concluded that $\mathrm{HNO}_{3}$ has the fastest and most effective demineralization speed. 
So, with the demineralization time (3 days), the impact on the surface of gutta percha almost did not change the structure. This allows to study the tooth sample as well as the obturation assembly - the gaps - the canal wall by demineralization without affecting gutta percha and the results.

\section{CONCLUSION}

Thermafil Gutta Percha has a good fit to the canal wall, which can seal the canal more easily and accurately. Thereby, the treatment of the pathological teeth will have better results. The material allows the doctor to fill the canal in three dimensions, preventing bacteria from re-entering the canal. With the Wave One canal shaping system, the canal is shaped with a minimum of taper, reducing the maximum amount of invasion. Thus, the amount of tooth structure will still be preserved as much as possible, but still achieve the shaping goal so that the obturation can seal the entire canal. Demineralization method allows to study effectively and honestly the section $1 / 3$ below the root of the tooth after the treatment using gutta percha gutta percha filling technique on experiment. After complete demineralization the sample should be transferred to another solution, without prolonged immersion in the demineralization solution.

\section{REFERENCES}

1. Bane K., Faye B., et al. (2015), "Root canal shaping by single-file systems and rotary instruments: a laboratory study", Iranian endodontic journal, 10(2), pp.135-139.

2. Bürklein S., Hinschitza K., et al. (2012), "Shaping ability and cleaning effectiveness of two single-file systems in severely curved root canals of extracted teeth: Reciproc and WaveOne versus Mtwo and ProTaper",
International endodontic journal, 45(5), pp.449-461.

3. Castelló-Escrivá R., Alegre-Domingo T., et al. (2012), "In vitro comparison of cyclic fatigue resistance of ProTaper, WaveOne, and Twisted Files", Journal of endodontics, 38(11), pp.1521-1524.

4. Chu C.H., Lo E.C.M., et al. (2005), "Outcome of root canal treatment using Thermafil and cold lateral condensation filling techniques", International endodontic journal, 38(3), pp.179-185.

5. Cunha R.S., Junaid A., et al. (2014), "Assessment of the separation incidence of reciprocating WaveOne files: a prospective clinical study", Journal of endodontics, 40(7), pp.922-924.

6. Gencoglu N., Helvacioglu D., et al. (2014), "Effect of six obturation techniques on filling of lateral canals", J Res Pract Dent, 2014, pp.1-7.

7. Sara Gamal., et al. (2019), "Investigating the Fracture Resistance and Sealing Ability of Teeth Obturated With a Novel Carrier-Based Obturation System: Guttacore as Compared with Thermafil Obturator A Comparative InVitro Study", Acta Scientific Dental Sciences 3.2, pp.68-72.

8. FRACCHIA, D., et al. (2020), GuttaCore Pink, Thermafil and Warm Vertically compacted gutta-percha retreatment: Time required and quantitative evaluation by using ProTaper files. Dental Materials Journal, 39(2), pp.229-235.

9. Abdulla, A., Elenjikal, M., Latheef, A., Kader, M., Ganapathy, S., Mohamed, A., Sainudeen, S. and Saquib, S., (2019). A comparative evaluation of five obturation techniques in the management of simulated internal resorptive cavities: An ex vivo study. Journal of Pharmacy And Bioallied Sciences, 11(6), p.450.

10.Vittoria, G., Pantaleo, G., Blasi, A., Spagnuolo, G., Iandolo, A. and Amato, M., (2018). Thermafil: A New Clinical Approach Due to New Dimensional Evaluations. The Open Dentistry Journal, 12(1), pp.173-180. 